\title{
INforum: Building strong partnerships
}

\author{
By Charlotte Hess and Gerald Bernbom
}

\section{An experiment in professional development collaboration}

E arly in 1993 librarians and technologists at Indiana University began discussions that grew into an ambitious collaborative program of professional development called INforum. An early report on this program appeared in CERL News in 1993. ${ }^{1}$ This article updates that story, through the first year of this program and its continuation into a second year.

\section{About INforum}

INforum is a collaborative program in professional development for librarians and technologists developed at Indiana University (IU). Key participants in the development of this program have been librarians from the Bloomington Library Faculty Council's Continuing Education Committee, information technology (IT) professionals from University Computing Services, and a member of the faculty from IU's School of Library and Information Science.

Planning for INforum began in the spring of 1993 , leading to a series of six program sessions developed and delivered during the 1993-94 academic year. Two themes were common to all the INforum programs: the importance of collaboration to the library and information technology professions; and the significant challenges that networked and electronic information present to both professions.

\section{Grassroots origins and professional development}

INforum began and evolved at the grassroots level. Awakened to the idea of the need for increased collaboration, a handful of librarians and technologists began informal discussions of this common theme. Other colleagues were brought into the discussions, which consistently enriched the breadth and scope of the questions and possible directions.

Once the momentum was started, the participants made a deliberate decision to maintain a grassroots orientation for INforum. The intention of the planners was to allow the greatest possible freedom and creativity in the design of the programs. It was hoped that each planner would feel free to view the questions from the perspective of: "What is important and interesting to me?" It was also a deliberate choice to make "professional development" the program direction for INforum. Professional development put the focus of attention for INforum on the individual, not on the organization; it emphasized individual development rather than organizational change; and it proceeded from a belief that real impact depends at least as much on people as on the structures they work in.

A program of professional development also emphasized the importance of understanding as the basis for action. As a project of collaborative learning, INforum was intencled to develop shared understanding among professionals from different backgrounds, to create the common conceptual ground that would be the key to joint action by librarians and technologists in the future.

Early planning for INforum began with an open-minded approach toward questions of the future of the professions. Program design was based on the belief that information skills are

Charlotte Hess is director of library and information services at Indiana University, Bloomington, e-mail: hess@indiana.edu; Gerald Bernbom is assistant director and senior information technology architect at Indiana University, e-mail: bernbom@indiana.edu. 
important to technologists, and that technical understanding is important to librarians. INforum was created to promote a positive climate and foundation for the future, an openended future based on professional partnerships and collaboration.

The focus on professional development encouraged intellectual exploration and individual expression/participation. The undertaking would require groups from both the libraries and the computing organization who were committed to its execution. The Continuing Education Committee of the Library Faculty Council and the ad hoc group from University Computing Services provided this basis of commitment. Both groups were encouraged by the local environment: the organizational climate in the libraries and in computing services was favorable, not hostile, to such an undertaking. The library administration was particularly enthusiastic about this theme and new approach to professional development.

While primarily a grassroots endeavor, the connection with the Libraries' Continuing Education Committee and the Computing Services' group of senior staff and managers did allow access to some traditional organizational structures of the university. This level of legitimate sponsorship facilitated the use of basic services needed for the program: scheduling rooms, reserving equipment, duplicating handouts, etc. In other words, this venture was low budget, but not no-budget.

While the details of the IU design are unique to our environment, what we did can apply to other institutions. The leadership for programs on this scale can come from many places: standing committees, ad hoc committees, individual library faculty, or computing professionals. Indeed, leadership can be found among any professional individuals or groups who have some degree of independence, some amount of cliscretionary time, and a favorable organizational climate. The bottom line is that library and IT professionals do not need to wait for senior administration to initiate professional activities.

\section{How did it work in practice?}

The process of planning INforum had both a macro- and a microstructure. On the macro level, the group began by establishing goals for the INforum program; deciding on logistics of session format, time, and location; and selecting six general session topics to be developed during the year.
On the micro level, the group clefined a planning structure and process. Each of the six sessions had a designated planning team comprised of at least one librarian and one technologist. Each team refined the topic, found appropriate speakers (preferably representing both professions), and coordinated the delivery and content of the presentations. In addition, the team was responsible for the descriptions, advertising, equipment reservations, and other details of the programs. Session teams gave periodic updates on its planning to the full INforum group, which offered feedback and suggestions.

The planning group made the decision not to administer evaluation forms to the audience at each session, but rather to rely on self-evaluation by the INforum planning group. As a means of self-evaluation, the full planning group met after each session to review the program, considering such factors as attendance, audience participation, personal observation, and audience feedback. Only after the final INforum session of the year was there a request for evaluation of the overall series, primarily to help in considering possible directions for the next year.

Sharing information about the INforum program with the library and IT communities was a priority for the program planners. Each session was promoted to the library and IT communities using various e-mail distribution lists. A gopher archive was set up to publish schedules, announcements, and summaries of the sessions. ${ }^{2}$ Responding to expressed interest from other campuses after the first session, the remaining programs were recorded on videotape. $^{3}$

\section{What did we do?}

The six INforum sessions offered cluring the 1993-94 academic year were a series of variations on the themes of collaboration and networked information. Each session had a specific focus, based on local interests and the timeliness of the topic. Most important to the goals of the INforum program, each session provided individual librarians, technologists, faculty, and others with the opportunity to share their experiences and insights with an audience of their colleagues.

\section{The sessions}

A brief summary of these six sessions will give some sense of the range and substance of the dialogue that INforum fostered. 
INforum 1: "Making Connections: National and Local Initiatives in Networked Information." This session was a panel presentation by several information professionals who described some of IU's local initiatives in networked information, and gave the audience an overview of many of the national organizations within each profession that work on issues in this area. The session provided technologists with some context of what was happening in the library profession, and vice versa. It was chosen as the best starting place for the INforum series: a get- acquainted meeting for librarians and technologists, and an introduction to each other and to each others professions.

INforum 2: "Two Worlds/Two Cultures: How Two Professions Approach the Wilderness of Internet Resources." This session was a dialogue among librarians, technologists, and faculty from library and information science. The discussion provided substantive information about networked information, today and tomorrow, and gave the audience a range of insights into the Internet phenomena and what it means to the information professions. This program was a good second step for INforum: a dialogue among the professions about a common set of interests, and a step toward the discovery of common ground and shared concerns.

INforum 3: "The Library Electronic Text Resource Service (LETRS).” This session brought together library faculty and staff, humanities faculty, and technology professionals to describe a case study of collaboration in practice between the library and technology professions at IU. The focus of the session was on electronic text research in the humanities, the support of this research by the library and IT communities, and the creation of a collaborative organization (jointly managed by a librarian and an information technologist) to provide this support.

INforum 4: "Copyright,Intellectual Property, and Electronic Information." This session brought together a diverse group-a librarian, a law professor, a publisher, and a library automation technologist - which provided substantive information on copyright law and its interpretation, and offered some conflicting viewpoints regarding the application of copyright law to electronic information.

INforum 5: "Information Anarchy and Information Order in the Electronic Age."
This panel discussion explored themes of anarchy and order as they relate to information quality and delivery of service by librarians and technologists. The panelists discussed standards and classification for traditional and electronic information, and offered several practitioners' viewpoints-a library cataloger, a campuswide information systems manager (CWIS), an SLIS faculty member, and a subject-area librarian-about creating order, or living with anarchy.

INforum 6: "The National Information Infrastructure (NII): National Issues and Local Impact for Technologists and Librarians." The final INforum session of the academic year invited the dean of the libraries and the associate vice-president for information technology from IU to address the topic of the National Information Infrastructure (NII) and to respond to issues and questions posed to them by individual librarians and information technologists regarding the local impact of this national initiative. This session, which was telecast systemwide, also summed up the year's discussion and reprised the overall INforum theme: bridging the gap between the library and technology professions, and focusing on their commonality as information professions. Our final program ended the year by looking forward: examining the NII as a major force in the future of librarians and technologists.

\section{A successful endeavor}

As we reached the end of a successful year with the INforum program, the joint planning group of librarians and technologists asked itself the questions: How should we proceed? Should we continue? What's next?

Looking back at the previous year's activities, INforum did make real the potential for ongoing communication between librarians and technologists. The topics, presenters, and participants at the individual INforum sessions began building a better understanding between these two professional groups, and identified several areas of shared interest and concern. The overall program provided a public forum for this dialogue, and gave a wide variety of information professionals the opportunity to reflect on, and share their insights into, some common problems of information technology and information management. More than thirty individual technologists, librarians, library staff, and university faculty members participated as speakers in the six INforum sessions 
of 1993-94. Total attendance over the six sessions numbered several hundred.

Progress toward our deeper goal, to build professional respect based on mutual understanding, was achieved in large measure through the quality and thoughtfulness of the dialogue among the presenters at each session, and between the presenters and their audiences. Professional respect was built, too, through the collaborative planning process that brought INforum into being.

\section{What's next?}

The joint planning group decided to continue INforum during the 1994-95 academic year. The Continuing Education Committee of the Library Faculty Council renewed its commitment to cosponsor the program. The ad hoc committee of computing services professionals expanded its membership. Out colleague from the Library and Information Science faculty agreed to participate for a second year. Feedback on the first year's INforum, gathered via e-mail from the overall program evaluation after the final session, has given guidance to planning the second year of this program.

The basic goals of INforum continue INforum has also refined and reshaped its activities in response to both survey results and our own self-evaluation. Some of the ideas that are shaping the program this year are: 1) focusing outward on the shared service mission of librarians and technologists-their similar roles in supporting the information needs of faculty, students, and scholarly activities of the university; 2) experimenting with other formats, in addition to the group presentations and panel discussions that were the basis of the first year's INforum program; 3) engaging more technologists and librarians in active dialogue through INforum; specifically, developing at least one ongoing discussion or working group on a topic of mutual interest; 4) delivering at least one program of widespread interest to librarians and technologists and other information professionals, featuring speakers of national reputation.

\section{Conclusion ... or what you might do}

What advice can we offer to colleagues at other institutions who are interested in this approach to professional development and library/ IT collaboration? Dialogue and grassroots leadership, more than any specific content or program structure, have been the keys to the success of INforum.
Find a librarian (or a technologist) and have lunch. Share your ideas, ask questions, raise concerns, discuss the issues that are important to you at the local level. As you talk and share ideas, imagine what you could do next to make something happen. When you look for partners, try to find the thinkers, the enthusiasts, and the doers, rather than just the "experts." Approach this endeavor with an open mind. Above all, be willing to talk and listen.

\section{Notes}

1. Charlotte Hess, "When worlds combine: Indiana University's INforum," CERL News 54 (October 1993): 514-15.

2. The online INforum archive can be found as follows: gopher client access: connect to gopher.indiana.edu, port 70, and follow the menu path: ==> The University: Information Services and Telnet Access $==>$ INforum - Library/UCS/SLIS Professional Development; World Wide Web Uniform Resource Locator (URL): gopher://gopher.indiana.edu:70/1/1/ theuniversity/inforum.

3. Videotape recordings of INforum presentations are cataloged and available through interlibrary loan. INforum 2 (Z674.82 .I59 T85 1993), INforum 3 (Z674.5 .I L47 1993), INforum 4 (KF2994 .C59 1994), INforum 5 (damaged during production-unavailable), INforum 6 (TK5105.5 .N375 1994).

Ed. note: Through the cooperation of CAUSE and ACRL, a companion article to this one appears in the fall 1994 issue of CAUSE/EFFECT.

\section{IU-Bloomington to host videoconference}

On October 28,1994 , Indiana University, Bloomington, will originate "Networked Information and the Scholar," a national satellite videoconference featuring internationally known panelists. The conference will focus on the growing use of networked information and how it can support the goals of higher education. The panelists will present their perspectives on the impact of electronic information and computer networks on teaching and research. For more information contact Margaret Lion or Eugene Brancolini at (812) 855-2101; fax: (812) 8550729; e-mail: televis@ucs.indiana.edu. 